\title{
Sustained erroneous near-infrared cerebral oxygen saturation in alert icteric patient with vanishing bile duct syndrome during and after liver transplantation - A case report -
}

\section{Yang Hoon Chung, So Jeong Lee, Bon Sung Koo, Ana Cho, Misoon Lee, Junwoo Park, and Sang Hyun Kim}

Received May 17, 2018

Revised June 22, 2018

Accepted July 6, 2018

\section{Corresponding author \\ Sang Hyun Kim, M.D., Ph.D. Department of Anesthesiology and Pain Medicine, Soonchunhyang University Bucheon Hospital, Soonchunhyang University College of Medicine, 170 Jomaru-ro, Wonmi- gu, Bucheon 14584, Korea \\ Tel: 82-32-621-6480 \\ Fax: 82-32-621-5322 \\ E-mail: skim@schmc.ac.kr ORCID \\ https://orcid.org/0000-0001-6267-7365 \\ It was presented at the 5th Annual Meeting of the Korean Society of Transplantation Anesthesiologists, May 2018, Kyungpook National University Chilgok Hospital, Daegu, Korea.}

Department of Anesthesiology and Pain Medicine, Soonchunhyang University Bucheon Hospital, Soonchunhyang University College of Medicine, Bucheon, Korea

\begin{abstract}
Monitoring cerebral oxygenation using a near infrared spectroscopy (NIRS) device is useful for estimating cerebral hypoperfusion and is available during liver transplantation (LT). However, high serum bilirubin concentration can interfere with NIRS because bilirubin absorbs near infrared light. We report a patient who underwent LT with a diagnosis of vanishing bile duct syndrome, whose regional cerebral oxygen saturation $\left(\mathrm{rSO}_{2}\right)$ remained below $15 \%$ even with alert mental status and $\mathrm{SpO}_{2}$ value of $99 \%$. The $\mathrm{rSO}_{2}$ values were almost fixed at the lowest measurable level throughout the intra- and postoperative period. We report a case of erroneously low $\mathrm{rSO}_{2}$ values during the perioperative period in a liver transplant recipient which might be attributable to skin pigmentation rather than higher serum bilirubin concentration.
\end{abstract}

Keywords: Bilirubin; Brain hypoxia; Hyperbilirubinemia; Liver transplantation; Nearinfrared spectroscopy; Oxymetry.
In healthy people, cerebral blood flow (CBF) is maintained steadily as long as the mean arterial pressure (MAP) and partial arterial $\mathrm{CO}_{2}$ pressure $\left(\mathrm{PaCO}_{2}\right)$ are within a certain range. The autoregulation of CBF is often impaired in patients with acute or chronic liver failure. In these patients, a change in MAP or $\mathrm{PaCO}_{2}$ will elicit either seriously increased or reduced CBF [1]. Factors likely to affect CBF or cerebral oxygenation include hemodynamic fluctuation, bleeding, and reperfusion syndrome during LT. However, monitoring methods for evaluating cerebral function such as cerebral perfusion pressure, jugular venous oximetry, and intracranial pressure are somewhat invasive and can lead to severe complications in patients with impaired hemostasis [2,3].

Near-infrared spectroscopy (NIRS) allows non-invasive and real time continuous monitoring of regional cerebral oxygen saturation $\left(\mathrm{rSO}_{2}\right)$ [4]. Monitoring cerebral oxygenation using a NIRS device is useful for estimating cerebral hypoperfusion during LT $[2,5]$. Unfortunately, high serum bilirubin concentration can interfere with NIRS because the bilirubin absorbs near infrared light. Therefore readings may be incorrect in patients with high serum bilirubin. Despite this limitation, it is used clinically as it reflects important trends

This is an Open Access article distributed under the terms of the Creative Commons Attribution Non-Commercial License (http://creativecommons.org/licenses/by-nc/4.0) which permits unrestricted non-commercial use, distribution, and reproduction in any medium, provided the original work is properly cited.

Copyright (C) the Korean Society of Anesthesiologists, 2019 
in most patients $[2,6]$. We report a patient who underwent LT with a diagnosis of vanishing bile duct syndrome whose $\mathrm{rSO}_{2}$ remained below $15 \%$ even with alert mental status. We could not observe even the trend of $\mathrm{rSO}_{2}$ values throughout the LT. This state remained even after bilirubin decreased.

\section{CASE REPORT}

A 79-year-old, $163 \mathrm{~cm}, 56 \mathrm{~kg}$, and dark skin-colored male was admitted for deceased donor LT due to vanishing bile duct syndrome. His past medical history consisted of hypertension diagnosed 10 years previously. Six months earlier, he suffered from nausea and right upper quadrant abdominal pain, and was diagnosed with acute cholecystitis. At that time, his total bilirubin value was $13.28 \mathrm{mg} / \mathrm{dl}$ and it remained in the range $10-20 \mathrm{mg} / \mathrm{dl}$ in spite of several interventions including endoscopic retrograde bile drainage. His final diagnosis was vanishing bile duct syndrome and LT was recommended.

Preoperative laboratory values were as follows: total bilirubin $20.7 \mathrm{mg} / \mathrm{dl}$, prothrombin time (international normalized ratio) 1.9, and hemoglobin $8.9 \mathrm{~g} / \mathrm{dl}$. When he entered the operating room, he was alert and was capable of ordinary conversation with the medical staff.

Anesthesia was induced with intravenous propofol 70 $\mathrm{mg}$ and rocuronium $50 \mathrm{mg}$. Maintenance of anesthesia was achieved with desflurane, $50 \%$ oxygen/air mixture (total flow

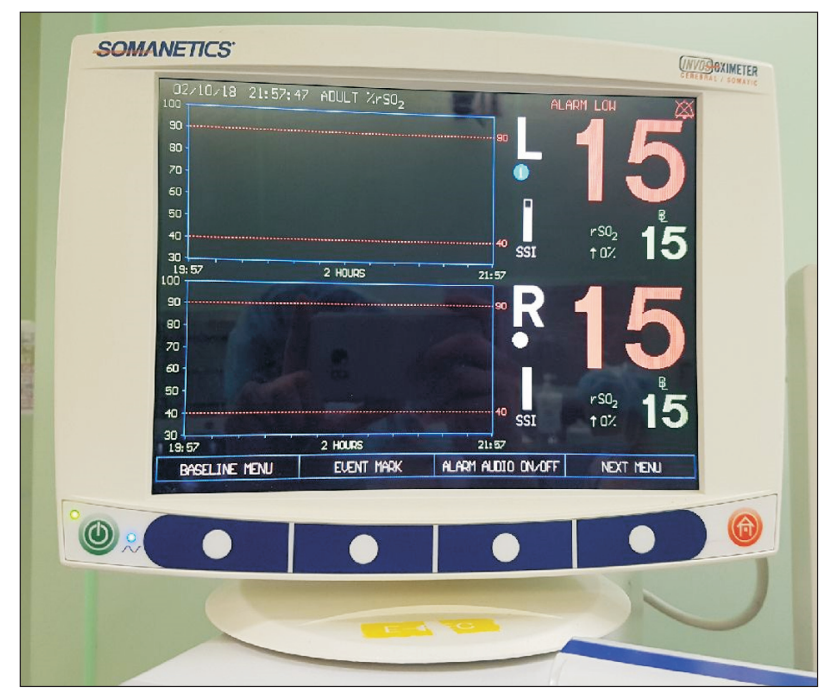

Fig. 1. Cerebral oximeter values before induction of anesthesia with alert mental status.
$3 \mathrm{~L} / \mathrm{min}$ ), continuous remifentanil (target controlled infusion dose $0-3 \mathrm{ng} / \mathrm{ml})$, and continuous rocuronium infusion ( $5 \mu \mathrm{g}$ / $\mathrm{kg} / \mathrm{min}$ ). Right radial and femoral artery were cannulated. An advanced venous access catheter (AVA, Edwards Lifesciences, USA) and 7 Fr triple lumen catheter (Arrow guard blue, Arrow international, USA) were inserted into the right internal jugular vein. A pulmonary artery catheter (SwanGanz CCOmbo V, Edwards Lifesciences, USA) was inserted via AVA catheter for cardiac output monitoring. Cerebral oximeter (INVOS 5100c, Medtronic, USA) and BIS (Covidien, USA) were also monitored. The $\mathrm{rSO}_{2}$ values before induction of anesthesia were $15 \%$ on both sides when the $\mathrm{SpO}_{2}$ value was $99 \%$ (Fig. 1).

Total anesthesia time was 340 minutes and all patient monitoring data was recorded in vital recorder program [7]. No remarkable events occurred. MAP was well maintained above $70 \mathrm{mmHg}$ with continuous norepinephrine infusion (0.1-0.3 $\mu \mathrm{g} / \mathrm{kg} / \mathrm{min})$. Hemoglobin value was above $7.8 \mathrm{~g} / \mathrm{dl}$ throughout the operation. Total crystalloid 2,750 ml, colloid (albumin) $750 \mathrm{ml}$, and salvaged blood by cell saver machine (AUTOLOG $^{\circledR}$, Medtronic, USA) $89 \mathrm{ml}$ were infused. No blood products were administered during the operation. The $\mathrm{rSO}_{2}$ values did not change on the left side, but a slight elevation from 15 to $30 \%$ was observed on the right side before portal vein reperfusion (Fig. 2).

The patient was transferred to surgical intensive care unit for postoperative recovery. The $\mathrm{rSO}_{2}$ was not monitored when the patient was in the intensive care unit. For further evaluation of the possible cause of abnormally low $\mathrm{rSO}_{2}$ values during surgery, we visited the patient three days after operation when his total bilirubin level was decreased to $9.82 \mathrm{mg} / \mathrm{dl}$. He was alert, responded correctly to our questions about his body condition, and his vital signs were stable; blood pres-

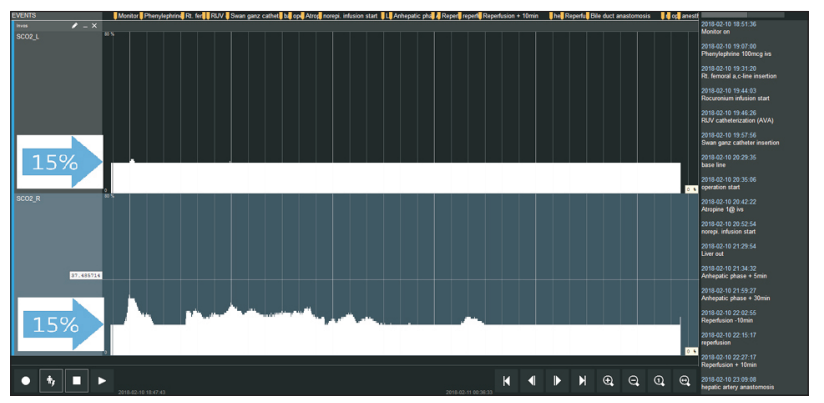

Fig. 2. A changing figure of regional cerebral oxygen saturation values during operation (recorded by vital recorder program). 
sure 141/63 (mean, 91) mmHg, and heart rate 53 beats/min. Hemoglobin level was $7.5 \mathrm{~g} / \mathrm{dl}$. When we monitored NIRS again, the $\mathrm{rSO}_{2}$ values were still recorded as $15 \%$ in both sides. He was discharged without any complication on postoperative day 21 .

\section{DISCUSSION}

Vanishing bile duct syndrome is a group of disorders which result in progressive destruction and 'vanishing' of intrahepatic bile ducts (ductopenia). Multiple etiologies including autoimmune, toxins, genetic abnormalities, infections, and neoplasms can lead to this disorder. Ductopenia is a pathologic term which refers to a loss of intrahepatic bile ducts, and eventually leads to cholestasis [8]. The specific cause of the disease in this current patient was not clear. His total bilirubin level was persistently high (10-20 ml/dl) about 6 months before LT. This long lasting hyperbilirubinemia seems to have caused significant skin pigmentation that led to the measurement error in NIRS and did not immediately disappear even after bilirubin concentration decreased. Under these circumstances, NIRS provides unreliable values in patients with vanishing bile duct syndrome during LT and this problem persists in spite of lowered bilirubin concentration after surgery. It indicates a critical limitation of NIRS.

According to the manufacturer's manual, the measurable range of $\mathrm{rSO}_{2}$ reading was 15-95\% (updated every 5-6 seconds) in the INVOS 5100c. Therefore, if $\mathrm{rSO}_{2}$ values were $<15 \%$, the machine displayed a result of $15 \%$. The $\mathrm{rSO}_{2}$ values of our patient were $15 \%$ on both sides before anesthesia induction. It was hard to believe that these $\mathrm{rSO}_{2}$ values reflected the real cerebral oxygen status, because he was alert and was capable of conducting ordinary conversation at that time.

The INVOS system uses dual wavelengths of near infrared light that are absorbed by oxy/deoxy hemoglobin (730 and $810 \mathrm{~nm}$ ). It is reported that the absorptivity of near infrared light by oxy/deoxy hemoglobin is well separated at $730 \mathrm{~nm}$ wavelength, but is similar at $810 \mathrm{~nm}$. Unfortunately, conjugated bilirubin has a peak absorptivity at $730 \mathrm{~nm}$. Bilirubin can be deposited in all tissue layers which can affect the capacity for assessing cerebral oxygenation by NIRS in patients with icterus [6,9].

Song et al. [2] reported that high total bilirubin and low hemoglobin are independent associated factors for low $\mathrm{rSO}_{2}$ values in patients with liver disease. They suggested that low $\mathrm{rSO}_{2}$ values in patients with icterus may be an artifact rather than true ischemia [2]. Madsen et al. [6] investigated 48 patients who underwent LT and reported that $\mathrm{rSO}_{2}$ was lowered but the internal jugular $\mathrm{O}_{2}$ saturation was not affected. They concluded that despite underestimating $\mathrm{rSO}_{2}$, the directional changes in $\mathrm{rSO}_{2}$ seemed to be observable even in patients with high bilirubin levels [6].

In the current case, we assume that $\mathrm{rSO}_{2}$ values were lower than the device was capable of measuring as described in the manufacturer's manual. Therefore, we could not detect even the directional changes in $\mathrm{rSO}_{2}$. His $\mathrm{rSO}_{2}$ remained unmeasurable until 3 days after the operation with alert mental status and lowered bilirubin level. One study revealed that changes in serum bilirubin concentration do not influence the $\mathrm{rSO}_{2}$ values during LT [10]. It seems likely that tissue pigmentation deposits may not disappear immediately in some patients [6]. Bilirubin can competitively absorb near infrared light and therefore play a role as confounder for $\mathrm{rSO}_{2}$ measuring. Bilirubin itself cannot affect either cerebral blood flow or cerebral oxygen uptake [6,9]. Hemoglobin levels were maintained above $8 \mathrm{~g} / \mathrm{dl}$, with MAP above $70 \mathrm{mmHg}$. Clinical causes other than an underestimation of $\mathrm{rSO}_{2}$ related to high bilirubinemia are hard to imagine.

The relationship between high serum bilirubin and falsely lower $\mathrm{rSO}_{2}$ has been reported. However, a case in which $\mathrm{rSO}_{2}$ was below the lower limit throughout LT and was maintained even after bilirubin diminished seem to be rare.

The limitation of this case report is that we did not use other methods for estimation of CBF such as transcranial Doppler sonography. We took it for granted the low $\mathrm{rSO}_{2}$ was an artifact because the patient was alert. If we had used the transcranial Doppler, we could have definitively ruled out the possibility of cerebral hypoperfusion. Moreover, it is unclear how long it might take to normalize the $\mathrm{rSO}_{2}$ after bilirubin decreased or what level of bilirubin is adequate for reliable $\mathrm{rSO}_{2}$ in icterus patients. There is a need for further research.

In conclusion, severe hyperbilirubinemia may make it impossible to estimate cerebral oxygenation using NIRS devices and furthermore, this limitation would persist even after the bilirubin decreased. Careful attention should be paid to the interpretation of NIRS values in patients with severe hyperbilirubinemia during LT. 


\section{CONFLICTS OF INTEREST}

No potential conflict of interest relevant to this article was reported.

\section{ORCID}

Yang Hoon Chung: https://orcid.org/0000-0002-9823-9030

So Jeong Lee: https://orcid.org/0000-0002-8935-2998

Bon Sung Koo: https://orcid.org/0000-0003-1578-6950

Ana Cho: https://orcid.org/0000-0002-6490-0353

Misoon Lee: https://orcid.org/0000-0001-7470-0921

Junwoo Park: https://orcid.org/0000-0002-5643-3767

\section{REFERENCES}

1. Pere P, Höckerstedt K, Isoniemi H, Lindgren L. Cerebral blood flow and oxygenation in liver transplantation for acute or chronic hepatic disease without venovenous bypass. Liver Transpl 2000; 6: 471-9.

2. Song JG, Jeong SM, Shin WJ, Jun IG, Shin K, Huh IY, et al. Laboratory variables associated with low near-infrared cerebral oxygen saturation in icteric patients before liver transplantation surgery. Anesth Analg 2011; 112: 1347-52.

3. Blei AT, Olafsson S, Webster S, Levy R. Complications of intra- cranial pressure monitoring in fulminant hepatic failure. Lancet 1993; 341: 157-8.

4. Casati A, Spreafico E, Putzu M, Fanelli G. [New technology for noninvasive brain monitoring: continuous cerebral oximetry]. Minerva Anestesiol 2006; 72: 605-25. Italian.

5. Plachky J, Hofer S, Volkmann M, Martin E, Bardenheuer HJ, Weigand MA. Regional cerebral oxygen saturation is a sensitive marker of cerebral hypoperfusion during orthotopic liver transplantation. Anesth Analg 2004; 99: 344-9.

6. Madsen PL, Skak C, Rasmussen A, Secher NH. Interference of cerebral near-infrared oximetry in patients with icterus. Anesth Analg 2000; 90: 489-93.

7. Lee HC, Jung CW. Vital Recorder-a free research tool for automatic recording of high-resolution time-synchronised physiological data from multiple anaesthesia devices. Sci Rep 2018; 8: 1527.

8. Reau NS, Jensen DM. Vanishing bile duct syndrome. Clin Liver Dis 2008; 12: 203-17.

9. Murkin JM, Arango M. Near-infrared spectroscopy as an index of brain and tissue oxygenation. Br J Anaesth 2009; 103 Suppl 1: i313.

10. Jun IG, Shin WJ, Park YS, Song JG, Kim YK, Hwang GS. Factors affecting intraoperative changes in regional cerebral oxygen saturation in patients undergoing liver transplantation. Transplant Proc 2013; 45: 245-50. 